\title{
Literature review on models for measuring the contribution of the information system to performance
}

\author{
Mohamed OMARI ${ }^{1}$, Hafida NIA ${ }^{2}$ \\ ${ }^{1}$ Faculty of Legal, Economic and Social Sciences Mohammedia, Hassan II University, Casablanca, Morocco \\ ${ }^{2}$ Faculty of Legal, Economic and Social Sciences Mohammedia, Hassan II University, Casablanca, Morocco
}

\begin{abstract}
The information system (IS) occupies an essential place in public and private establishments and managers are constantly seeking to create value by implementing information systems that generate tangible and intangible gains. To do this, they are constantly investing in information systems to improve their performance and generate results. However, these managers are constantly questioning the relevance and effectiveness of these investments. The information system poses a problem of definition given that it is a multidimensional concept, and also of measurement. The objective of this paper is to review the literature on the different models for measuring the contribution of information systems to the performance of organizations, based on the resource theory and the behavioral approach in a processual perspective. This literature review allows us to identify and present these models, with a view to testing them in various contexts.
\end{abstract}

Keywords: Information system, performance, measurement models.

\section{Introduction}

The information system (IS) plays a crucial role and is currently the beating heart of the organization. The challenge for managers is to achieve a high level of cohabitation between different generations of technology, on the same platform, without condemning their use and to ensure their alignment with the needs of different processes.

The study of the evaluation of the contribution of IS to performance is a dominant research theme (Vitari and Pillet, 2019) of interest to both researchers and professionals. This craze can be explained by the fact that this topic occupies the attention of managers who are constantly seeking to justify IS investments and show their contribution to value creation and performance improvement, and of researchers who are trying to improve their understanding of when, why and how to evaluate IS, in order to agree on a unanimous and standard definition and also to measure its contribution to performance.

The objective of this paper is to review the literature on the different models for measuring the contribution of IS to the performance of organizations, based on the resource theory and the behavioral approach in a processual perspective.

\section{Models of user satisfaction:}

In the research literature, user satisfaction has been used as an indicator to measure the success of IS. This measure, described as perceptual and subjective, reflects the attitudes of users towards the IS with which they interact. Indeed, there is an instrument for measuring user satisfaction, which is composed of 39 variables measuring users' reactions to IS (Hou, 2012). This instrument has been taken up and 
improved by other researchers, grouping other indicators that may affect user satisfaction into three dimensions (Aggelidis and Chatzoglou, 2012):

$>$ The quality of the information produced by the IS.

$>$ The quality of IS services and the relationship with IS personnel.

$>$ The knowledge and involvement of IS users.

Other authors have tried to take into consideration the IS usage environment and develop a new measurement instrument consisting of five dimensions: information content, information accuracy, information format, ease of use of the IS, and speed of obtaining information (Turan et al., 2015).

A meta-analysis of the literature related to user satisfaction was conducted (Adam Mahmood et al., 2000). The authors highlight the relationship between the individual and the context in which they operate and find that user satisfaction is influenced by: perceived benefits, organizational support, and user characteristics.

Perceived benefits represent the benefits derived by the organization from the use of an IS, characterized by the ease of use and the usefulness of the system. Organizational support includes the user's attitudes towards the IS, organizational support through training programs, and the perceived attitude of the management team towards IS projects. User characteristics include the user's experience and skills in using the IS as well as their involvement in the development of the system (Dwivedi, et al.,2012; Ayranci et al., 2015; Ferreras-Fernández et al., 2016).

Figure No. 1 illustrates the findings of this meta-analysis.

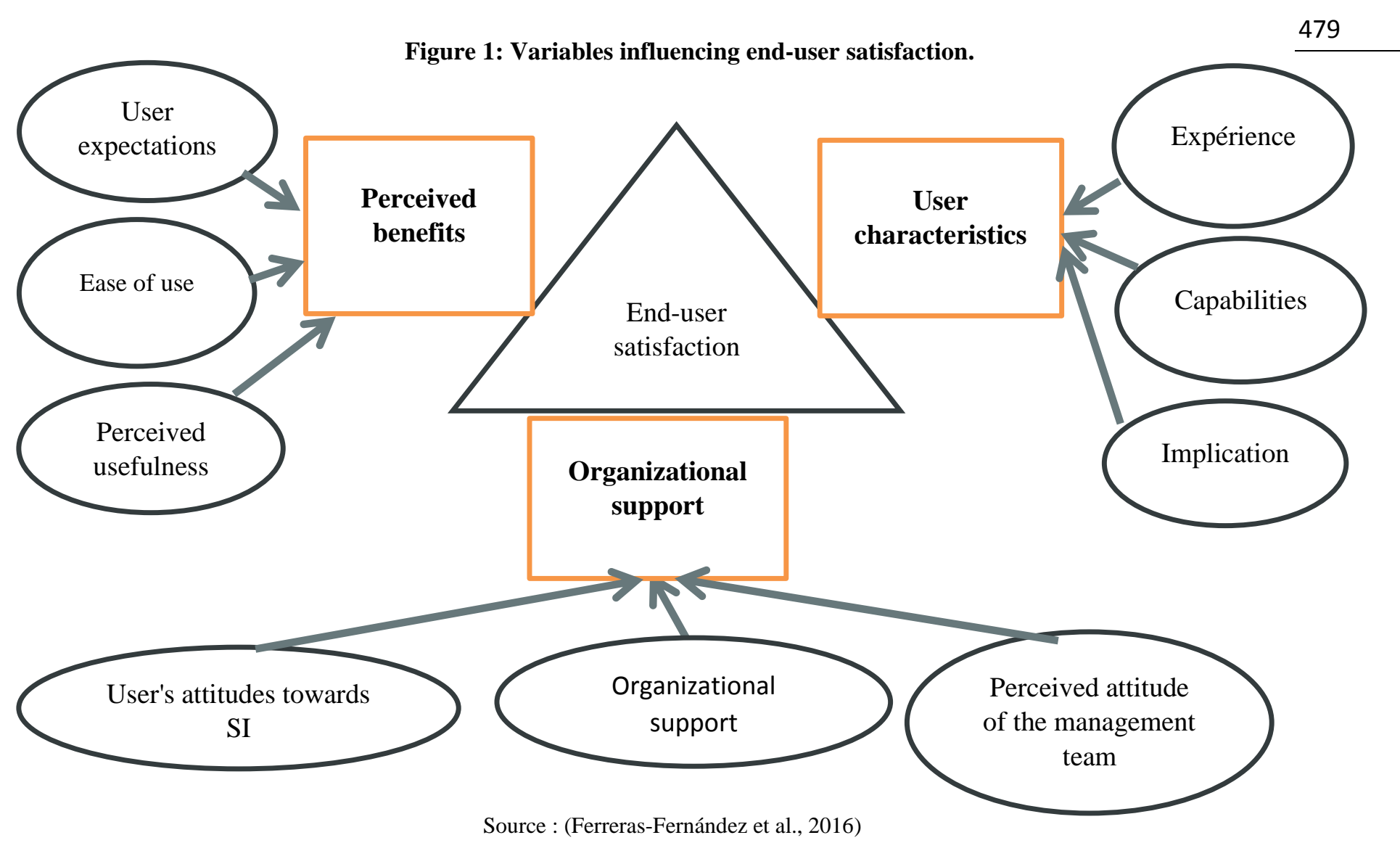


However, measuring IS success by user satisfaction has been criticized in research using DeLone and McLean's IS success model. "Variables such as user engagement or the role played by leaders cannot be considered as indicators of IS performance measures, but rather as variables that may impact IS performance" (Dwivedi, et al., 2012; Debei, Jalal and Lozi, 2013; Hsu et al., 2014).

\section{Models of IS use:}

There are two main models, which have been designed and developed, to explain IS acceptance and use, these are the technology acceptance model and the task-technology fit model, both models use as a measure of IS success; IS usage.

\section{A. The technology acceptance model:}

To explain why some IS are more easily accepted than others, some authors have used the theory of reasoned action. This theory states that an individual's behavior is a function of his or her intention to adopt that behavior, which is determined by personal interest and social influence. Based on this theory, the Technology Acceptance Model (TAM) is developed to explain the behavior of users of information technology in different populations and contexts. This model states that an individual's use of the system depends on his or her intention to adopt this behavior, which is a function of his or her attitude toward use and perceived usefulness. Attitude towards use is determined by perceived usefulness and perceived ease of use, which depends on external variables, including the characteristics of the system. Figure No. 2 illustrates the TAM model (Bellaaj, 2010; Kéfi, 2010; Wünderlich, et al., , 2013; Tarhini,et al., 2014; Bobillier Chaumon, 2016; Howard et al., 2017).

Figure 2: Technology Acceptance Model

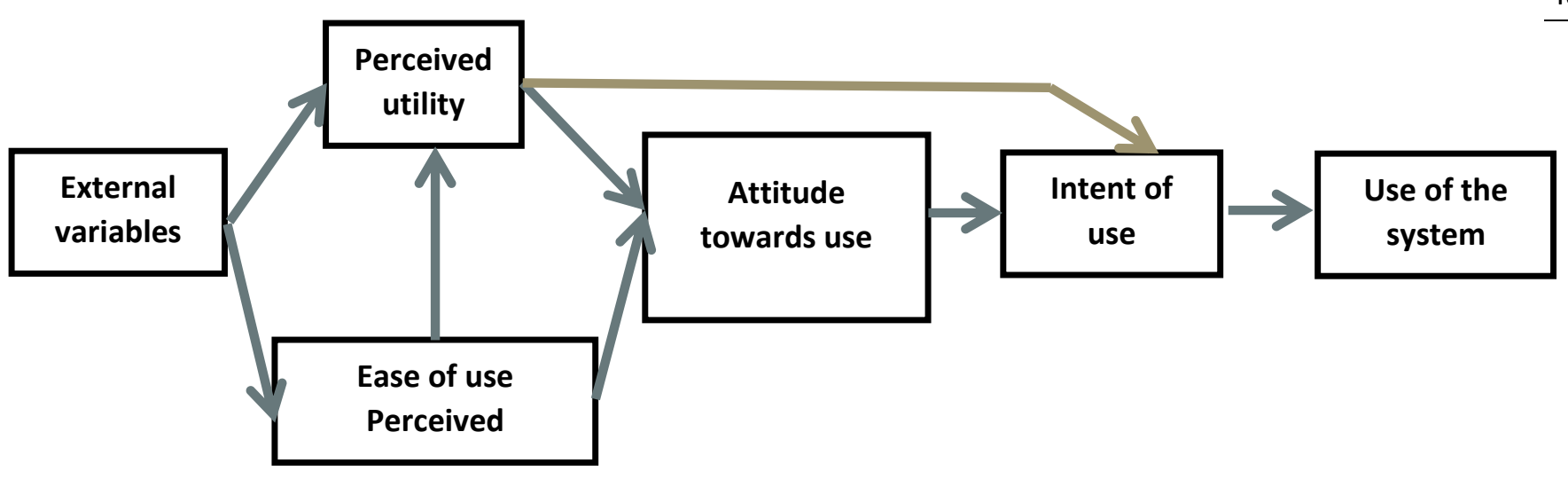

Source: (Bellaaj, 2010)

Perceived usefulness is defined as the degree to which a person believes that using a system improves their job performance. Perceived ease of use is defined as the degree to which a person believes that using a system does not require effort. Perceived usefulness and ease of use are highly correlated with usage, however the former variable is more influential on usage behavior (Rashed et al., 2010; Fazil et al., 2016; Haydar, 2017; Mghizou and Chafik, 2017; Benabid, 2019).

As soon as it was introduced, several researchers started to do studies on this model with the aim of comparing it with the reasoned action model, testing it in different contexts and finally extending it by introducing other measurement variables, and then proposing an update of the first model giving birth to a second model known as TAM 2 offering more details on the factors influencing the perception of a system's usefulness such as subjective norms, image, task importance, and quality of use results. 
However, even with the addition of other variables, the TAM model only explains 30-40\% of the variance in usage behavior. These authors were able to conclude that incorporating social and organizational variables into TAM will improve its predictive power (Lee et al, 2003; Venkatesh and Bala, 2008; Holden and Karsh, 2010; Kim and Park, 2012; Mishra et al., 2014).

After a review of the literature (Venkatesh et al., 2003; 2011; 2016) synthesize the elements of previous technology acceptance models and present a unified model of technology acceptance called UTAUT "Unified Theory of Acceptance and Use of Technology" (Figure No. 3). The UTAUT model has four basic determinants of intention to use and use: expected performance, expected effort, social influence, and facilitating conditions. Expected performance is defined as "the degree to which an individual believes that using the system will help them improve their job performance" (Venkatesh, et al, 2011; 2016). This factor brings together variables from other models such as perceived usefulness. Expected effort represents "the degree of ease associated with using the system" (Venkatesh,et al, 2016) . Social influence reflects "the degree to which an individual perceives that it is important for others to believe that he or she can use the new system" (Venkatesh, et al, 2011; 2016). This factor combines a variety of variables such as the subjective norms used in TAM 2. Finally, enabling conditions represent "the degree to which an individual believes that the technical and organizational infrastructure supports the use of the system" (Venkatesh, et al , 2011; 2016). The relationships between these determinants of intent and use are moderated by the following variables: gender, age, experience, and willingness to use.

In the UTAUT, the use of a technology depends on the intention to use and the facilitating conditions, i.e. the technical and organizational conditions that will facilitate this use. The intention to use is in turn determined by the expected performance, the expected effort and the social influence.

Figure No. 3 illustrates the UTAUT model (Venkatesh et al., 2003; Venkatesh and Bala, 2008; Venkatesh, et al., 2011; Ashraf,et al., 2014; Zuiderwijk, and Dwivedi, 2015; Venkatesh, et al., 2016).

Figure 3: illustration of the UTAUT model

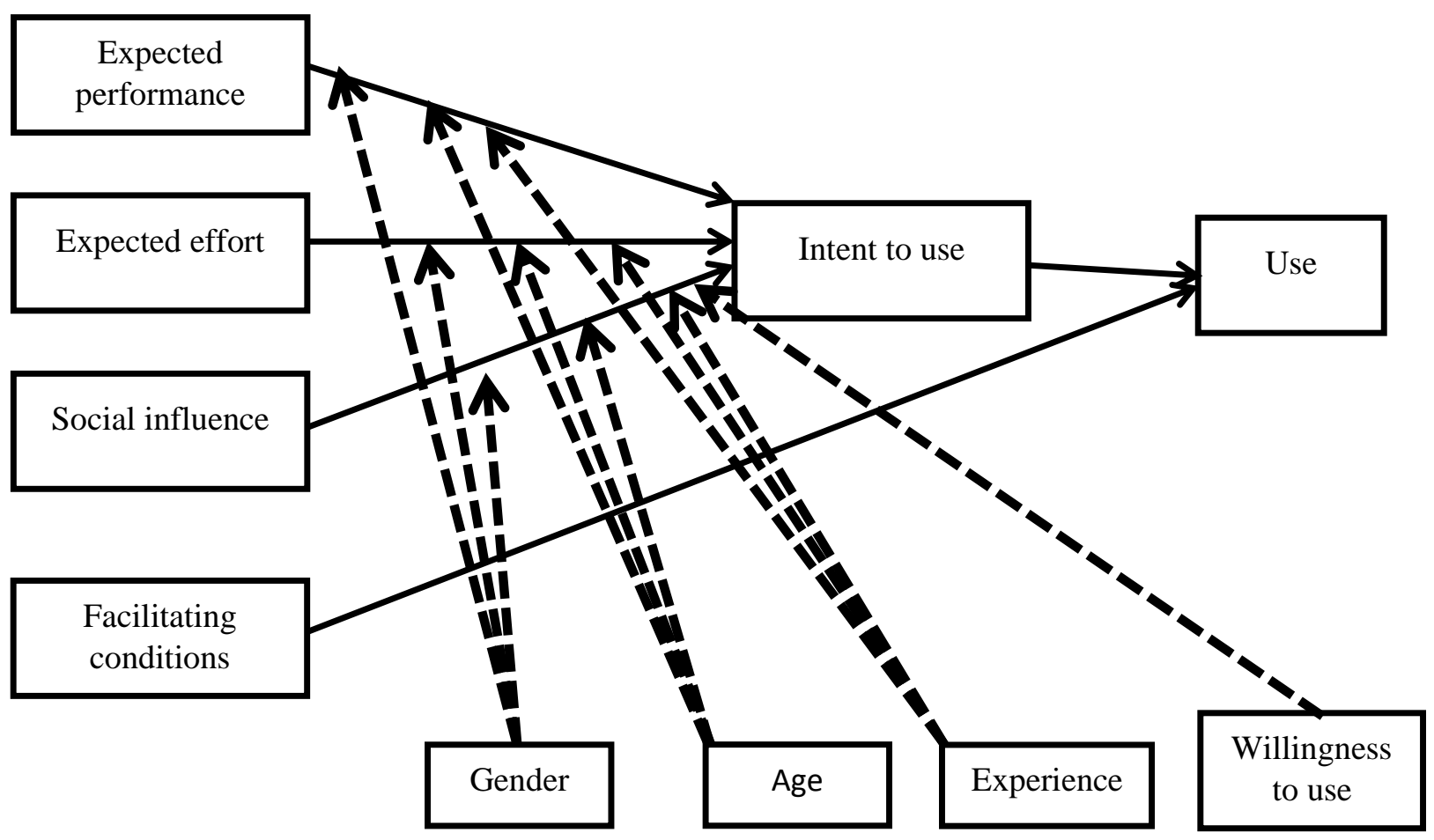

Source : (Venkatesh, et al., 2011) 
The technology acceptance model emphasizes the role of perceived usefulness and ease of use in the acceptance and use of a technology. Yet, several studies have questioned the choice of the use variable as a measure of IS success, but use is not necessarily synonymous with success, especially when it is mandatory, and also use does not necessarily improve performance, as we may find ourselves in a situation where the technology is not suited to the tasks at hand (Hou, 2012; Shih and Chen, 2013).

We now turn to a second model based on the behavioral approach and the theory of reasoned action, which is the task-technology fit model in which the perception of technology varies across tasks.

\section{B. The task-technology fit model:}

The task-technology fit model studies the relationship between technology and task, it is based on five dimensions: technology characteristics, task characteristics, task-technology fit, use and performance.

The characteristics of the technology represent the functionalities of the organization's information system. The characteristics of the task to be performed by the individual are measured by the interdependence between tasks, the complexity of the task and the hierarchical level of the user.

Task-technology fit represents the degree of fit between the characteristics of the technology and those of the task, and can be measured by different indicators such as; accessibility, compatibility, quality of data and information, fit to needs, relevance, compliance, ease of learning, and relationship with designers.

Usability represents the behavior of an individual when using a technology to perform a task and is measured by the degree of perceived dependence on the system.

Performance is measured by the user's perceived improvement in effectiveness, efficiency, or quality of task completion (Parkes, 2013). Figure No. 4 illustrates this model.

Figure 4: Task-technology fit model.

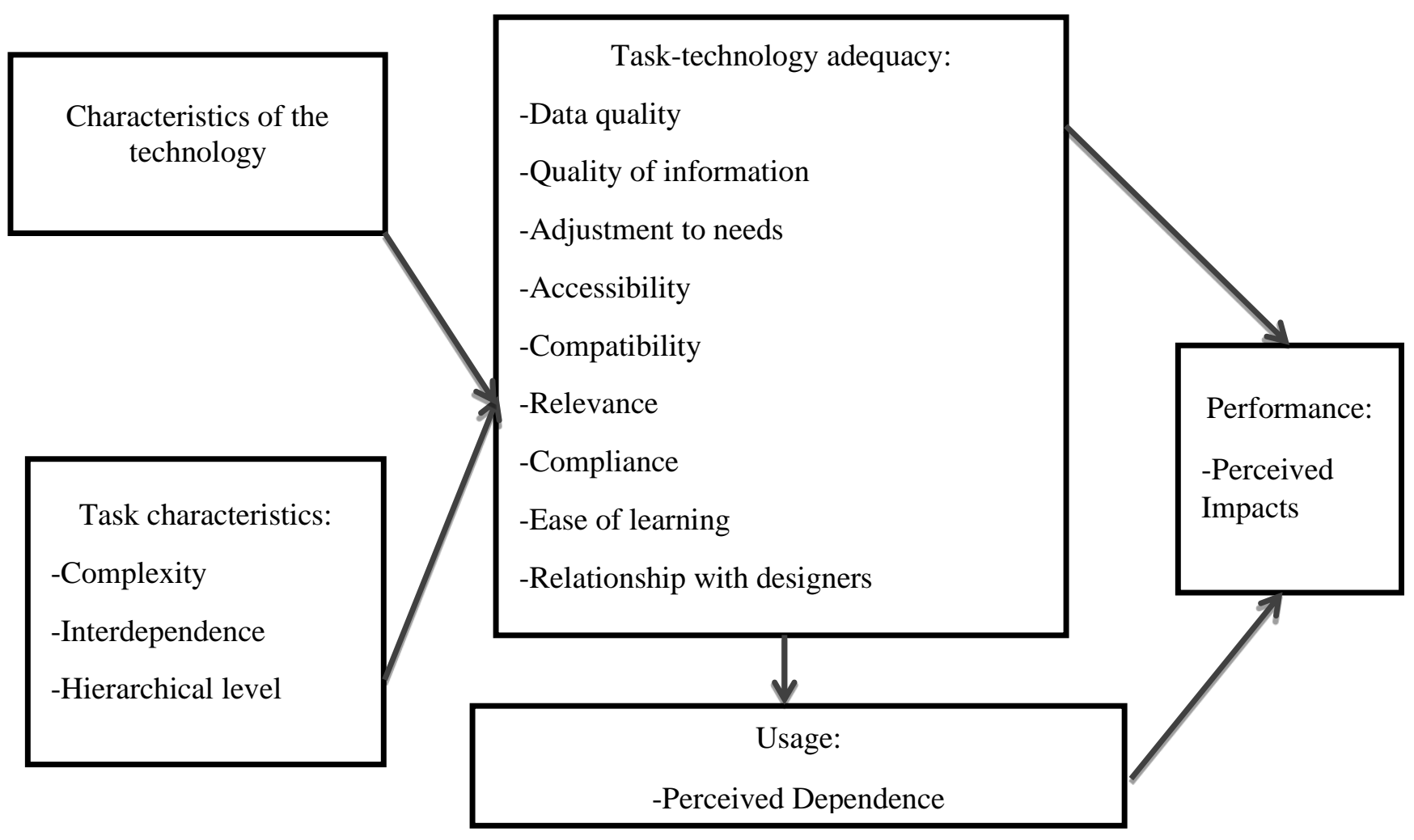

Source: (Parkes, 2013) 
In this model, technology can lead to performance if it is appropriate for the tasks to be performed. Indeed, the impact perceived by users on performance depends on the use and the task-technology fit. The latter is determined by the characteristics of the task and the characteristics of the technology. This model has been taken up by other researchers to apply to different technologies and in other contexts (Lin and Wang, 2012; Tomei, 2012; Skik, et al., 2017; Wu and Chen, 2017).

Thus, the task-technology fit model complements the technology acceptance model in explaining IS use. The difference between these two models is that the former seeks to predict performance while the latter seeks to predict usage. However, usage is not necessarily synonymous with performance. Nor is it a characteristic of IS success, but rather a consequence of IS success (Shahreki and Nakanishi, 2016).

\section{The IS success model:}

The IS success model, "ISSM" (Information Systems Success Model), represents an important reference in the IS evaluation research field and is the starting point for several subsequent studies.

\section{A. The ISSM model (1):}

In 1992, DeLone and McLean proposed a model for measuring IS success. This model links six interdependent dimensions: system quality, information quality, system use, user satisfaction, individual impact and organizational impact.

System quality represents the specific qualities of the information processing system. Information quality measures the quality of the output of the information system. The use of the system concerns the consumption of the IS outputs. User satisfaction reflects the user's response to the use of the IS output. The individual impact measures the effect of the IS on the user's behavior. Finally, organizational impact measures the effect of IS on organizational performance.

The quality of the system and the quality of the information affect both the use of the system and user satisfaction. The latter two variables are interrelated and determine the individual impact that affects the organizational impact (Petter and McLean, 2009; Urbach and Müller, 2012).

Figure No. 5 illustrates the IS success model

Figure 5: ISSM model (1)

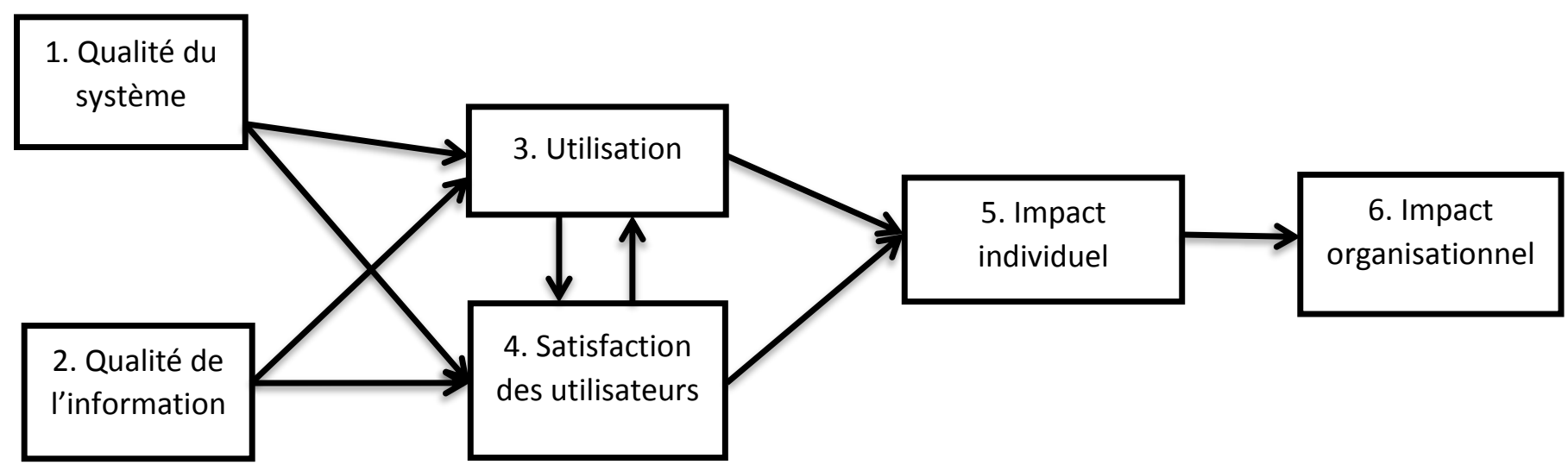

Source: (Petter and McLean, 2009; Urbach and Müller, 2012). 
The ISSM model has been partially or comprehensively tested in different contexts, and it has become a theoretical basis for several studies (Petter, et al., 2012).

However, several criticisms have been endorsed to this model, related to its causal and processual nature and since it considers that utilization is not a characteristic of IS success, but rather a consequence of IS success. For this reason, he proposed a causal model in which he replaced the use of the system in Delone and McLean's model with perceived utility. Other criticisms have also been made of this model, but this time of methodological nature in relation to its development, since Delone and McLean do not expose their epistemological approach and do not explain well the relationships between the variables (Urbach and Müller, 2012).

Also, the indicators used, in this model, to measure the effectiveness of the IS focus only on the products of the IS function, hence the importance of the services rendered to users by the ISD as a key and primary element. Therefore, they consider that the quality of service is an indicator of IS success, and suggest that it be integrated into the ISSM model. This variable can be measured using Parasuraman's SERVQUAL model, which represents a tool for measuring users' expectations and perceptions of the quality of the service provided through five main dimensions: responsiveness, assurance, reliability, empathy and physical facilities.

Faced with the criticisms endorsed to the original model and based on the studies that tried to validate it, Delone and McLean then revised their model in 2003 (Gorla, 2011; Jiang et al., 2012).

\section{B. The ISSM Model (2):}

Taking into account the criticisms cited above, DeLone and McLean expressed their opinion on the processual and causal nature of their model by maintaining its use as a dependent variable, and taking into consideration the change in the environment and context as an important element to operationalize the variables, and then they made modifications to this initial model, introducing a new independent variable that is the quality of service. The measurement indicators selected are intention to use and use, while the indicator for measuring individual and organizational impacts is net benefit, which measures the impact on the individual, the organization and society (Urbach and Müller, 2012).

Therefore, this new model has seven variables: system quality, information quality, service quality, intention to use, usage, user satisfaction, and net benefit (Urbach and Müller, 2012). System quality measures the performance of the IT system in terms of reliability, convenience, ease of use, functionality as well as other system parameters.

Information quality represents the quality of outputs offered by the IS, measured in terms of timeliness, accuracy, and completeness... The quality of service provided by the IS department to users is measured by reliability, assurance, responsiveness, and empathy. Intent to use measures the expectation of future use of an IS or its outputs, while the use variable measures their actual use. User satisfaction reflects their approval or satisfaction with the IS and its outputs. Finally, the net benefits represent the effect that an IS has on an individual, a group, an organization, an industry, a society, etc. This variable is often measured in terms of the number of users. This variable is often measured in terms of individual and organizational performance, perceived usefulness and effect on work practices (Petter and McLean, 2009). 
Figure 6: illustration of the ISSM (2).

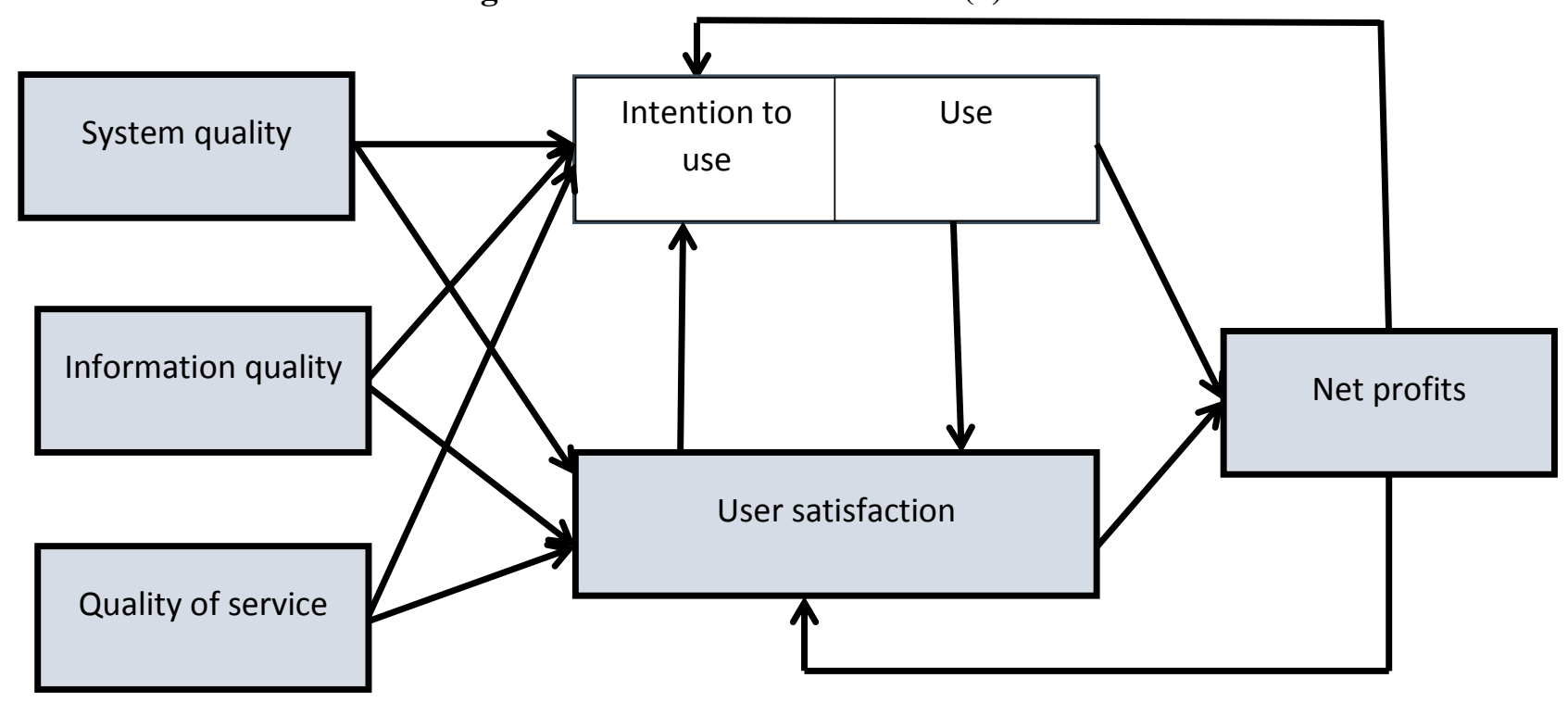

Source: (Urbach and Müller, 2012)

This model measures IS success or effectiveness at the organizational level (Sedera and Gable, 2004; Gable et al., 2008; Dwivedi, et al., 2012), and has been tested in different contexts, either in part (Bernroider, 2008; Gorla, et al, 2010) or in aggregate (Wang and Liao, 2008) or with some modifications (Chang and King, 2005).

Indeed (Wang and Liao, 2008; Lin, 2014; Ramdan, et al., 2014) tested the overall IS success model in e-government. Their results confirm the relationships among the dimensions of the model except the one between IT system quality and usage.

(Chang and King, 2005) modified the ISSM model based on the economic input-output function to propose a new performance model, which states that performance is determined by business process performance and IS performance which depend on IS "outputs" produced by IS "inputs".

(Gorla et al., 2010; Gorla and Somers, 2014) used only four dimensions of the ISSM model, which are: system quality, information quality, service quality and organizational impact. Their study shows that there is a significant direct or indirect organizational impact of system quality, information quality and service quality. These authors also found that information quality is the primary mediator between system quality and organizational impact.

Based on the studies using the ISSM model, the meta-analysis of (Petter and McLean, 2009) report that the majority of the relationships are validated except for those: between service quality and user satisfaction and between service quality and usage, while the relationship between service quality and intention to use has not been tested.

(Rouibah, et al., 2015) tested the model for the first time in the Arab world in e-commerce. The results largely support what the other studies have confirmed. The most important difference between the results of this study and previous studies is the finding that although service quality influences value, it has no impact on user satisfaction in an Arab context. 


\section{Conclusion}

Computing and information systems have revolutionized the world of organizations, bringing with them new problems. Among these issues, we find the problem of defining IS and its measurement. This work allows us to better define the issue of measuring the contribution of IS to performance. To do so, we have relied on a literature review to extract the different measurement models in order to better understand the problem of adoption to enable organizations to successfully implement their IS and to benefit from its advantages.

\section{References}

[1] C. Vitari et J.-C. Pillet, «Le réseau social de la communauté francophone des chercheurs en Systèmes d'Information », Systèmes Inf. Manag., vol. 24, no 1, Art. no 1, 2019, doi: 10.3917/sim.191.0087.

[2] C.-K. Hou, « Examining the effect of user satisfaction on system usage and individual performance with business intelligence systems: An empirical study of Taiwan's electronics industry », Int. J. Inf. Manag., vol. 32, no 6, Art. no 6, déc. 2012, doi: 10.1016/j.ijinfomgt.2012.03.001.

[3] V. P. Aggelidis et P. D. Chatzoglou, « Hospital information systems: Measuring end user computing satisfaction (EUCS) », J. Biomed. Inform., vol. 45, no 3, Art. no 3, juin 2012, doi: 10.1016/j.jbi.2012.02.009.

[4] A. Turan, A. Ö. Tunç, et C. Zehir, « A Theoretical Model Proposal: Personal Innovativeness and User Involvement as Antecedents of Unified Theory of Acceptance and Use of Technology », Procedia - Soc. Behav. Sci., vol. 210, p. 43-51, déc. 2015, doi: 10.1016/j.sbspro.2015.11.327.

[5] M. Adam Mahmood, J. M. Burn, L. A. Gemoets, et C. Jacquez, « Variables affecting information technology enduser satisfaction: a meta-analysis of the empirical literature », Int. J. Hum.-Comput. Stud., vol. 52, no 4, Art. no 4, avr. 2000, doi: 10.1006/ijhc.1999.0353.

[6] E. Ayranci, Z. Kalyoncu, S. Guney, M. Arslan, et S. Guney, « Analysis of the Relationship between Emotional Intelligence and Stress Caused by the Organisation: A Study of Nurses », Bus. Intell. J., vol. 5, no 2, Art. no 2, 2015, doi: 10.13140/RG.2.1.4815.0883.

[7] Y. K. Dwivedi, M. R. Wade, et S. L. Schneberger, Information systems theory: explaining and predicting our digital society, vol. 28. New York, NY: Springer, 2012.

[8] T. Ferreras-Fernández, H. Martín-Rodero, F. J. García-Peñalvo, et J. A. Merlo-Vega, « The systematic review of literature in LIS: an approach », New York, NY, USA, 2016, p. 291-296. doi: 10.1145/3012430.3012531.

[9] T. Ferreras-Fernández, H. Martín-Rodero, F. J. García-Peñalvo, et J. A. Merlo-Vega, « The systematic review of literature in LIS: an approach », New York, NY, USA, 2016, p. 291-296. doi: 10.1145/3012430.3012531.

[10] M. M. A. Debei, D. Jalal, et E. A. Lozi, « Measuring web portals success: a respecification and validation of the DeLone and McLean information systems success model », Int. J. Bus. Inf. Syst., vol. 14, no 1, Art. no 1, 2013 , doi: 10.1504/IJBIS.2013.055555.

[11] M.-H. Hsu, C.-M. Chang, K.-K. Chu, et Y.-J. Lee, « Determinants of repurchase intention in online group-buying: The perspectives of DeLone \& McLean IS success model and trust », Comput. Hum. Behav., vol. 36, p. 234-245, juill. 2014, doi: 10.1016/j.chb.2014.03.065.

[12] M. Bellaaj, « Technologies de l'information et performance organisationnelle: diifférentes approches d'évaluation. », HAL Arch.-Ouvert., vol. 20, p. 1-20, 2010.

[13] M.-E. Bobillier Chaumon, «L'acceptation située des technologies dans et par l'activité : premiers étayages pour une clinique de l'usage », Psychol. Trav. Organ., vol. 22, no 1, Art. no 1, mars 2016, doi: 10.1016/j.pto.2016.01.001.

[14] R. Howard, L. Restrepo, et C.-Y. Chang, « Addressing individual perceptions: An application of the unified theory of acceptance and use of technology to building information modelling », Int. J. Proj. Manag., vol. 35, no 2, Art. no 2, févr. 2017, doi: 10.1016/j.ijproman.2016.10.012.

[15] H. Kéfi, " Mesures perceptuelles de l'usage des systèmes d'information: application de la théorie du comportement planifié », Humanisme Entrep., vol. 297, no 2, Art. no 2, 2010, doi: 10.3917/hume.297.0045.

[16] A. Tarhini, K. Hone, et X. Liu, « The effects of individual differences on e-learning users' behaviour in developing countries: A structural equation model », Comput. Hum. Behav., vol. 41, p. 153-163, déc. 2014, doi: 10.1016/j.chb.2014.09.020. 
[17] N. V. Wünderlich, F. v. Wangenheim, et M. J. Bitner, «High Tech and High Touch: A Framework for Understanding User Attitudes and Behaviors Related to Smart Interactive Services », J. Serv. Res., vol. 16, no 1, Art. no 1, févr. 2013, doi: 10.1177/1094670512448413.

[18] M. Benabid, « Facteurs influençant l'intention d'achat dans le contexte des sites d'information d'actualité en ligne : une étude empirique par la théorie de l'acceptation technologique », Rev. Quest. Manag., vol. n²3, no 1, Art. no 1, 2019, doi: 10.3917/qdm.191.0117.

[19] A. Fazil, W. Rupert, et A. Ejaz, «Investigating the influence of the most commonly used external variables of TAM on students' Perceived Ease of Use (PEOU) and Perceived Usefulness (PU) of e-portfolios », Comput. Hum. Behav., vol. 63, p. 75-90, oct. 2016, doi: 10.1016/j.chb.2016.05.014.

[20] A. Haydar, « L'impact des valeurs culturelles des salariés sur leur utilisation des Systèmes d'Information (SI): Etude empirique dans le contexte syrien », Univ. Damas Syr., vol. 40, p. 75-114, 2017.

[21] H. Mghizou et K. Chafik, « L'impact individuel perçu d'un logiciel d'automatisation d'audit par les auditeurs financiers marocains: Résultats d'une Enquête exploratoire. », Rev. Econ. Gest. Société, vol. 1, no 12, Art. no 12, 2017.

[22] C. A. A. Rashed, A. Azeem, et Z. Halim, « Effect of Information and Knowledge Sharing on Supply Chain Performance: A Survey Based Approach », J. Oper. Supply Chain Manag., vol. 3, no 2, Art. no 2, déc. 2010, doi: 10.12660/joscmv3n2p61-77.

[23] R. J. Holden et B.-T. Karsh, « The Technology Acceptance Model: Its past and its future in health care », J. Biomed. Inform., vol. 43, no 1, Art. no 1, févr. 2010, doi: 10.1016/j.jbi.2009.07.002.

[24] J. Kim et H.-A. Park, « Development of a Health Information Technology Acceptance Model Using Consumers' Health Behavior Intention », J. Med. Internet Res., vol. 14, no 5, Art. no 5, oct. 2012, doi: 10.2196/jmir.2143.

[25] Y. Lee, K. A. Kozar, et K. R. T. Larsen, « The Technology Acceptance Model: Past, Present, and Future », Commun. Assoc. Inf. Syst., vol. 12, no 50, Art. no 50, 2003, doi: 10.17705/1CAIS.01250.

[26] D. Mishra, I. Akman, et A. Mishra, « Theory of Reasoned Action application for Green Information Technology acceptance », Comput. Hum. Behav., vol. 36, p. 29-40, juill. 2014, doi: 10.1016/j.chb.2014.03.030.

[27] V. Venkatesh et H. Bala, « Technology Acceptance Model 3 and a Research Agenda on Interventions », Decis. Sci., vol. 39, no 2, Art. no 2, mai 2008, doi: 10.1111/j.1540-5915.2008.00192.x.

[28] V. Venkatesh, M. Morris G., G. B. Davis, et F. D. Davis, « User acceptance of information technology: toward a unified view », MIS Q., vol. Vol. 27, no 3, Art. no 3, 2003.

[29] V. Venkatesh, J. Thong, et X. Xu, «Unified Theory of Acceptance and Use of Technology: A Synthesis and the Road Ahead », J. Assoc. Inf. Syst., vol. 17, no 5, Art. no 5, mai 2016, doi: 10.17705/1jais.00428.

[30] V. Venkatesh, T. A. Sykes, et Xiaojun Zhang, « A Revised UTAUT for EMR System Adoption and Use by Doctors », in 2011 44th Hawaii International Conference on System Sciences, Kauai, HI, USA, janv. 2011, p. 1-10. doi: 10.1109/HICSS.2011.1.

[31] A. R. Ashraf, N. (Tek) Thongpapanl, et S. Auh, « The Application of the Technology Acceptance Model under Different Cultural Contexts: The Case of Online Shopping Adoption », J. Int. Mark., vol. 22, no 3, Art. no 3, sept. 2014, doi: 10.1509/jim.14.0065.

[32] A. Zuiderwijk, M. Janssen, et Y. K. Dwivedi, « Acceptance and use predictors of open data technologies: Drawing upon the unified theory of acceptance and use of technology », Gov. Inf. Q., vol. 32, no 4, Art. no 4, oct. 2015 , doi: 10.1016/j.giq.2015.09.005.

[33] Y.-Y. Shih et C.-Y. Chen, « The study of behavioral intention for mobile commerce: via integrated model of TAM and TTF », Qual. Quant., vol. 47, no 2, Art. no 2, févr. 2013, doi: 10.1007/s11135-011-9579-x.

[34] A. Parkes, «The effect of task-individual-technology fit on user attitude and performance: An experimental investigation », Decis. Support Syst., vol. 54, no 2, Art. no 2, janv. 2013, doi: 10.1016/j.dss.2012.10.025.

[35] A. Parkes, « The effect of task-individual-technology fit on user attitude and performance: An experimental investigation », Decis. Support Syst., vol. 54, no 2, Art. no 2, janv. 2013, doi: 10.1016/j.dss.2012.10.025.

[36] W.-S. Lin et C.-H. Wang, « Antecedences to continued intentions of adopting e-learning system in blended learning instruction: A contingency framework based on models of information system success and tasktechnology fit », Comput. Educ., vol. 58, no 1, Art. no 1, janv. 2012, doi: 10.1016/j.compedu.2011.07.008.

[37] M. Skik, A. Bouzaiene, et L. Hikkerova, « Les préalables à la mise en place d'un CRM bancaire: Le cas d'une banque tunisienne », Rev. Gest. 2000, vol. 34, no 1, Art. no 1, 2017, doi: 10.3917/g2000.341.0181.

[38] L. A. Tomei, Éd., Advancing Education with Information Communication Technologies: Facilitating New Trends, $1^{\circ}$ édition. IGI Global, 2012. doi: 10.4018/978-1-61350-468-0. 
[39] B. Wu et X. Chen, « Continuance intention to use MOOCs: Integrating the technology acceptance model (TAM) and task technology fit (TTF) model », Comput. Hum. Behav., vol. 67, p. 221-232, févr. 2017, doi: 10.1016/j.chb.2016.10.028.

[40] J. Shahreki et H. Nakanishi, « The Relationship between Task Technology Fit and Individual Performance: Case Study in Hotel Industry in Malaysia », J. Soft Comput. Decis. Support Syst., vol. 3, no 6, Art. no 6, 2016.

[41] S. Petter et E. R. McLean, « A meta-analytic assessment of the DeLone and McLean IS success model: An examination of IS success at the individual level », Inf. Manage., vol. 46, no 3, Art. no 3, avr. 2009, doi: 10.1016/j.im.2008.12.006.

[42] N. Urbach et B. Müller, « The Updated DeLone and McLean Model of Information Systems Success », in Information Systems Theory, vol. 28, Y. K. Dwivedi, M. R. Wade, et S. L. Schneberger, Éd. New York, NY: Springer New York, 2012, p. 1-18. doi: 10.1007/978-1-4419-6108-2_1.

[43] S. Petter et E. R. McLean, « A meta-analytic assessment of the DeLone and McLean IS success model: An examination of IS success at the individual level », Inf. Manage., vol. 46, no 3, Art. no 3, avr. 2009, doi: 10.1016/j.im.2008.12.006.

[44] N. Urbach et B. Müller, « The Updated DeLone and McLean Model of Information Systems Success », in Information Systems Theory, vol. 28, Y. K. Dwivedi, M. R. Wade, et S. L. Schneberger, Éd. New York, NY: Springer New York, 2012, p. 1-18. doi: 10.1007/978-1-4419-6108-2_1.

[45] S. Petter, W. DeLone, et E. McLean, « The Past, Present, and Future of "IS Success », J. Assoc. Inf. Syst., vol. 13, no 5, Art. no 5, 2012.

[46] N. Gorla, « An assessment of information systems service quality using SERVQUAL », ACM SIGMIS Database, vol. 42, no 3, Art. no 3, sept. 2011, doi: 10.1145/2038056.2038060.

[47] J. J. Jiang, G. Klein, N. Parolia, et Y. Li, « An Analysis of Three SERVQUAL Variations in Measuring Information System Service Quality », vol. 15, no 2, Art. no 2, 2012.

[48] G. Gable, D. Sedera, Queensland University of Technology, Australia, T. Chan, et Queensland University of Technology, Australia, « Re-conceptualizing Information System Success: The IS-Impact Measurement Model », J. Assoc. Inf. Syst., vol. 9, no 7, Art. no 7, juill. 2008, doi: 10.17705/1jais.00164.

[49] D. Sedera et G. Gable, «A Factor and Structural Equation Analysis of the Enterprise Systems Success Measurement Model », in International Conference of Information Systems, Washington D.C., USA, 2004, p. 449-464.

[50] E. W. N. Bernroider, « IT governance for enterprise resource planning supported by the DeLone-McLean model of information systems success », Inf. Manage., vol. 45, no 5, Art. no 5, juill. 2008, doi: 10.1016/j.im.2007.11.004.

[51] N. Gorla, T. M. Somers, et B. Wong, « Organizational impact of system quality, information quality, and service quality », J. Strateg. Inf. Syst., vol. 19, no 3, Art. no 3, sept. 2010, doi: 10.1016/j.jsis.2010.05.001.

[52] Y.-S. Wang et Y.-W. Liao, « Assessing eGovernment systems success: A validation of the DeLone and McLean model of information systems success », Gov. Inf. Q., vol. 25, no 4, Art. no 4, oct. 2008, doi: 10.1016/j.giq.2007.06.002.

[53] J. C.-J. Chang et W. R. King, « Measuring the Performance of Information Systems: A Functional Scorecard », J. Manag. Inf. Syst., vol. 22, no 1, Art. no 1, avr. 2005, doi: 10.1080/07421222.2003.11045833.

[54] C. A. Lin, Communication Technology and Social Change: Theory and Implications, 1re éd. Routledge, 2014. doi: 10.4324/9781410615411.

[55] S. M. A. Ramdan, B. A. Yousif Nurdiana, et B. S. Kamarudin, «E-Government Systems Success Evaluating under Principle Islam: A Validation of the Delone and Mclean Model of Islamic Information Systems Success. », Acad. Res. Int., vol. 5, no 2, Art. no 2, mars 2014.

[56] N. Gorla et T. M. Somers, « The impact of IT outsourcing on information systems success », Inf. Manage., vol. 51, no 3, Art. no 3, avr. 2014, doi: 10.1016/j.im.2013.12.002.

[57] K. Rouibah, P. B. Lowry, et L. Almutairi, « Dimensions of Business-to-Consumer (B2C) Systems Success in Kuwait: Testing a Modified DeLone and McLean IS Success Model in an E-Commerce Context », J. Glob. Inf. Manag., vol. 23, no 3, Art. no 3, juill. 2015, doi: 10.4018/JGIM.2015070103. 